\title{
Evaluating Potentials of Integrated Application of Plant Residues and Inorganic Fertilizers in Enhancing Soil Fertility Status and Maize (Zea mays L.) yield
}

\author{
B. Osundare, F.O. Fawole \\ Department of Crop, Soil and Environmental Science, Ekiti State University, Ado - Ekiti, Nigeria. \\ *Corresponding Author: B. Osundare, Department of Crop, Soil and Environmental Sciences, Ekiti State \\ University, Ado - Ekiti, Nigeria.
}

\begin{abstract}
In view of the limitations or inadequacies of sole use of organic or inorganic fertilizers, hence, there is a dire need to critically appraise the potential of combined application of organic and inorganic fertilizers as a nutrient source to improve soil fertility and ensure balanced crop nutrition. To this end, an experiment was initiated to assess the effects of integrated application of Centrosema pubescens residue and certain inorganic fertilizers on soil chemical properties and maize (Zea mays L.) performance. The experiment was carried out at the Teaching and Research Farm of the Ekiti State University, Ado - Ekiti, Nigeria, during 2015 and 2016 cropping seasons. The experiment was laid out in a randomized complete block design, with three replicates. The plant residues and inorganic fertilizers treatments included: sole Centrosema pubescens residue (SCPR); Centrosema pubescens residue (CPR)+Ammonium sulphate (AS) $(C P R+A S)$; Centrosema pubescens residue $+N P K(C P R+N P K)$; Centrosema pubescens residue + single superphosphate $(S S P)(C P R+S S P)$ and no fertilizer application (NFA). The results obtained indicated existence of significant $(P=0.05)$ differences among the different Centrosema pubescens residue - based fertilizer combination treatments as regards their effects on soil chemical properties and maize yield. Relative to initial nutrient status of the soil before cropping, at the end of 2015 cropping season, CPR+SSP, $C R P+N P K$ and SCPR increased soil organic carbon (SOC) by 21, 18 and 15\%, respectively, contrasting decreases of 31 and $51 \%$ for $C P R+A S$ and C, respectively. Similarly, at the end of 2016 cropping season, $C P R+S S P, C R P+N P K$ and SCPR increased SOC by 24, 23 and 20\%, respectively, contrasting decreases of 44 and $61 \%$ for $C P R+A S$ and $C$, respectively. At the end of 2015 cropping season, CPR+SSP, CRP $+N P K$ and SCPR increased total N by 19, 47 and 35\%, respectively, contrasting decreases of 51 and $67 \%$ for $C P R+A S$ and $C$, respectively. At the end of 2016 cropping season, CPR+SSP, CRP+NPK and SCPR increased total $N$ by 19,47 and 35\%, respectively, contrasting decreases of 51 and $67 \%$ for $C P R+A S$ and $C$, respectively. Mean values of maize yield data over the two years of experimentation indicated that integrated application of Cenrosema pubescens residue and inorganic fertilizers significantly increased maize grain yield from 0.81 t ha $a^{-1}$ for $C$ to $1.70,1.91,2.33$ and $2.10 \mathrm{th}^{-1}$ for the respective $S C P R, C P R+A S, C P R+N P K$ and $C P R+S S P$.
\end{abstract}

\section{INTRODUCTION}

Agricultural productivity of tropical soils is adversely affected by the inherently low fertility status of the soils, characterized by low - activity - clay (LAC), organic matter, nitrogen, phosphorus, buffering capacities and exchangeable basic cations (Adenle, 2010; Pestov, 2012).

Recognizing the constraints or limitations for the utilization of the low- activity- clay tropical soils for continuous crop production has necessitated growing search for professionally sound soil fertility management practices, which in recent time, has included the adoption of appropriate and adequate fertilizer packages, involving the use of organic and/ or inorganic fertilizers (Atete, 2012; Lege, 2012). The use of inorganic or mineral fertilizers in maintaining soil fertility has been reported to be ineffective, due to certain limitations. Some of these limitations include: low efficiency (as a result of losses through volatilization and leaching), declined soil organic matter content, nutrient imbalance, soil acidification, as well as soil physical degradation, with resultant increased incidence of soil erosion (Kader, 2012). Asides, high cost and occasional scarcity of mineral fertilizers have posed a lot of problem to their use as nutrient sources (Guman, 2011). 
The limitations of the use of mineral fertilizers to improve soil fertility and crop yield has consequently informed shift of attention to the use of organic fertilizers for soil fertility improvement, especially, the highly weathered tropical soils (Ame, 2012; Kader, 2012). However, the use of organic fertilizers, too, has certain demerits of slow release and non - synchronization of nutrient release with period of growth for most short - season crops, as well as being required in large quantities to sustain crop production, which may not readily be available to the small - scale farmers (Keary, 2014).

Plant residues and other biomass constitute an important resource; as they have a great potential of improving the physical, chemical and biological properties of soil after decomposition (Aribe, 2003; Udeata, 2008; Nottidge et al. 2010). Singh (2005) noted that the amount of N, P and K and certain micronutrients contained in the plant residues is 60 times as high as the nutrients applied through mineral or synthetic fertilizers.

In view of the limitations of sole application of organic or inorganic fertilizers in improving soil fertility and crop yield, there is a dire need to critically appraise the potential of combined application of organic and inorganic fertilizers as a nutrient source to improve soil fertility, and hence, ensure balanced crop nutrition. Consequent upon this, this research was initiated to assess the effects of integrated application of Centrosema pubescens residues and certain inorganic fertilizers on soil chemical properties and maize performance.

\section{MATERIALS AND MethodS}

Study site: A field experiment was carried out at the Teaching and Research Farm of the Ekiti State University, Ado - Ekiti, Ekiti State, Nigeria, during 2016 and 2017 cropping seasons. The soil of the study site belongs to the broad group Alfisol (SSS, 2003). The soil was strongly leached, with low to medium organic matter content. Prior to this investigation, the study site had earlier been under intensive and continuous cultivation of a variety of arable crops for many years.

Experimental design and treatments: The experiment was laid out in a randomized complete block design with three replications. The plant residues and inorganic fertilizers treatments included: sole Centrosema pubescens residue (SCPR); Centrosema pubescens residue (CPR)+Ammonium sulphate (AS) $(\mathrm{CPR}+\mathrm{AS})$; Centrosema pubescens residue+NPK (CPR+NPK); Centrosema pubescens residue+single superphosphate (SSP) (CPR+SSP) and no fertilizer application (NFA). SSP, NPK, AS, and CPR were applied at the rates of $260 \mathrm{~kg} \mathrm{ha}^{-1}, 350 \mathrm{~kg} \mathrm{ha}^{-1}, 300 \mathrm{~kg} \mathrm{ha}^{-1}$ and $7 \mathrm{t} \mathrm{ha}^{-1}$, respectively (Awani, 2012; Balogun, 2012; Lege, 2012). Each plot size was $3 \mathrm{~m} \mathrm{x} 3 \mathrm{~m}$.

Collection and analysis of soil samples: Prior to cropping, 35 core soil samples, randomly collected from $0-15 \mathrm{~cm}$ soil depth, were mixed inside a plastic bucket to form a composite sample, which was analyzed for chemical properties. Similarly, at the end of cropping, another sets of soil samples were collected in each treatment plot and analyzed.

The soil samples were air - dried, ground, and passed through a $2 \mathrm{~mm}$ sieve. The processed soil samples were analyzed in accordance with the soil analytical procedures, as outlined by the International Institute of Tropical Agriculture (IITA) (1989).

Planting: Maize was planted at a spacing of $75 \mathrm{~cm}$ x $30 \mathrm{~cm}$, with two seeds per stand $(888,888$ maize plants ha $\left.{ }^{-1}\right)$.

Weeding was carried out at 3,6 and 9 weeks after planting (WAP), using a hand hoe.

At harvest, data were collected on maize yield and yield components.

Data analysis: All the data collected on soil chemical properties and maize grain yield were subjected to analysis of variance (ANOVA), and treatment means were compared, using the Duncan Multiple Range Test (DMRT) at 5\% probability level.

\section{Results}

\section{Chemical composition of Centrosema pubescens residue used in the experiment}

Table 1 shows chemical composition of Centrosema pubescens residue used in the experiment 
Evaluating Potentials of Integrated Application of Plant Residues and Inorganic Fertilizers in Enhancing Soil Fertility Status and Maize (Zea mays L.) yield

Table 1. Chemical analysis of Centrosema pubescens residue used in the experiment

\begin{tabular}{|c|c|}
\hline Nutrient & Value \\
\hline Organic carbon $\left(\mathrm{g} \mathrm{kg}^{-1}\right)$ & 1.17 \\
\hline Nitrogen $\quad\left(\mathrm{g} \mathrm{kg}^{-1}\right)$ & 2.38 \\
\hline $\mathrm{C} / \mathrm{N}$ ratio & 0.49 \\
\hline Phosphorus & 0.51 \\
\hline Potassium & 0.44 \\
\hline Calcium & 0.53 \\
\hline Magnesium & 0.54 \\
\hline Sodium & 0.40 \\
\hline
\end{tabular}

\section{Chemical properties of soil in the study site prior to investigation}

Table 2 shows the chemical properties of soil in the study site before investigation

Table 2. Chemical properties of the soil before investigation

\begin{tabular}{|lc|}
\hline Soil properties & Values \\
\hline $\mathrm{pH}$ & 5.7 Organic \\
carbon $\left(\mathrm{g} \mathrm{kg}^{-1}\right)$ & 0.71 \\
Total nitrogen $\left(\mathrm{g} \mathrm{kg}^{-1}\right)$ & 0.43 \\
Available phosphorus $\left(\mathrm{mg} \mathrm{kg}^{-1}\right)$ & 0.61 \\
Exchangeable bases $\left(\mathrm{cmol} \mathrm{kg}^{-1}\right)$ & \\
Potassium & 0.31 \\
Calcium & 0.44 \\
Magnesium & 0.34 \\
Sodium & 0.26 \\
Exchangeable Acidity & 0.23 \\
Effective Cation Exchangeable Capacity (ECEC) & 1.58 \\
\hline
\end{tabular}

Chemical properties of the soil as affected by integrated application of plant residues and inorganic fertilizers after 2015 cropping season

Table 3 shows the effects of integrated application of plant residues and inorganic fertilizers on soil chemical properties after 2015 cropping season. Relative to initial nutrient status of the soil before cropping, at the end of 2015 cropping season, CPR+SSP and CRP+NPK and SCPR increased pH of the soil by 61, 51 and 42\%, respectively, contrasting decreases of 12 and $26 \%$ for CPR+AS and C, respectively. Similarly, CPR+SSP, CRP+NPK and SCPR increased soil organic carbon (SOC) by 21, 18 and $15 \%$, respectively, contrasting decreases of 31 and $51 \%$ for CPR+AS and C, respectively. CPR+SSP and CRP+NPK and SCPR increased total $\mathrm{N}$ by 19, 47 and 35\%, respectively, contrasting decreases of 51 and $67 \%$ for $\mathrm{CPR}+\mathrm{AS}$ and $\mathrm{C}$, respectively. CPR+SSP and CRP+NPK and SCPR increased available $\mathrm{P}$ by 28,20 and $11 \%$, respectively, contrasting decreases of 38 and $61 \%$ for $\mathrm{CPR}+\mathrm{AS}$ and $\mathrm{C}$, respectively. CPR+SSP, CRP+NPK and SCPR increased exchangeable K by 45, 71 and $13 \%$, respectively, contrasting decreases of 23 and $45 \%$ for CPR+AS and C, respectively. $\mathrm{CPR}+\mathrm{SSP}$ and CRP+NPK and SCPR increased exchangeable $\mathrm{Ca}$ by 27, 16 and 9\%, respectively, contrasting decreases of 41 and $57 \%$ for CPR+AS and $\mathrm{C}$, respectively. CPR+SSP, CRP+NPK and SCPR increased exchangeable Mg by 29, 24 and 15\%, respectively, contrasting decreases of 15 and $47 \%$ for CPR+AS and C, respectively. CPR+SSP, CRP+NPK and SCPR increased exchangeable Na by 35, 27 and 19\%, respectively, contrasting decreases of 27 and $50 \%$ for CPR+AS and C, respectively.

Table 3. Chemical properties of the soil as affected by Centrosema pubescens residue and inorganic fertilizers after 2015 cropping season.

\begin{tabular}{|c|c|c|c|c|c|c|c|c|}
\hline \multirow{2}{*}{$\begin{array}{l}\text { Treatments } \\
(\mathrm{CPR}+\text { IF) }\end{array}$} & \multirow[t]{2}{*}{$\mathbf{p H}$} & \multirow{2}{*}{$\frac{\text { Org. C. }}{\left(\mathrm{g} \mathrm{kg}^{-1}\right)}$} & \multirow{2}{*}{$\frac{\text { Total N }}{\left(\mathrm{g} \mathrm{kg}^{-1}\right)}$} & \multirow{2}{*}{$\frac{\text { Avail. } \mathbf{P}}{\left(\mathrm{mg} \mathrm{kg}^{-1}\right)}$} & \multicolumn{4}{|c|}{ Exchangeable bases $\left(\mathrm{cmol} \mathrm{kg}^{-1}\right)$} \\
\hline & & & & & $\mathrm{K}$ & $\mathrm{Ca}$ & $\mathrm{Mg}$ & $\mathrm{Na}$ \\
\hline Check & $4.2 \mathrm{e}$ & $0.35 \mathrm{e}$ & $0.20 \mathrm{e}$ & $0.24 \mathrm{e}$ & $0.17 \mathrm{e}$ & $0.19 \mathrm{~d}$ & $0.18 \mathrm{c}$ & $0.13 \mathrm{c}$ \\
\hline SCPR & $8.1 \mathrm{c}$ & $0.82 \mathrm{a}$ & $0.52 b$ & $0.68 \mathrm{c}$ & $0.39 \mathrm{c}$ & $0.48 b$ & $0.39 \mathrm{a}$ & $0.31 \mathrm{a}$ \\
\hline $\mathrm{CPR}+\mathrm{AS}$ & $5.0 \mathrm{~d}$ & $0.47 b$ & $0.28 \mathrm{~d}$ & $0.38 \mathrm{~d}$ & $0.24 \mathrm{~d}$ & $0.26 \mathrm{c}$ & $0.29 b$ & $0.19 b$ \\
\hline $\mathrm{CPR}+\mathrm{NPK}$ & $8.6 b$ & $0.84 \mathrm{a}$ & $0.57 \mathrm{a}$ & $0.73 b$ & $0.53 \mathrm{a}$ & $0.51 b$ & $0.42 \mathrm{a}$ & $0.33 \mathrm{a}$ \\
\hline $\mathrm{CPR}+\mathrm{SSP}$ & $9.2 \mathrm{a}$ & $0.86 \mathrm{a}$ & $0.47 \mathrm{c}$ & $0.78 \mathrm{a}$ & $0.45 b$ & $0.56 \mathrm{a}$ & $0.44 \mathrm{a}$ & $0.35 \mathrm{a}$ \\
\hline
\end{tabular}


Evaluating Potentials of Integrated Application of Plant Residues and Inorganic Fertilizers in Enhancing Soil Fertility Status and Maize (Zea mays L.) yield

Mean values in the same column followed by the same letter(s) are not significantly different at $\mathrm{P}=$ 0.05 (DMRT). CPR+IF, Centrosema pubescens residue+inorganic fertilizer; SCPR, sole Centrosema pubescens residue; CPR+AS, Centrosema pubescens residue+ammonium sulphate, CPR+SSP, Centrosema pubescens residue+single superphosphate

\section{Chemical properties of the soil as affected by Centrosema pubescens residue and inorganic fertilizers after 2016 cropping season.}

Table 4 shows the effects of integrated application of plant residues and inorganic fertilizers on soil chemical properties after 2016 cropping season. Relative to initial nutrient status of the soil before cropping, at the end of 2016 cropping season, CPR+SSP and CRP+NPK and SCPR increased pH of the soil by 67, 56 and 47\%, respectively, contrasting decreases of 21 and $39 \%$ for CPR+AS and C, respectively. Similarly, CPR+SSP, CRP+NPK and SCPR increased soil organic carbon (SOC) by 24, 23 and 20\%, respectively, contrasting decreases of 44 and $61 \%$ for CPR+AS and C, respectively. $\mathrm{CPR}+\mathrm{SSP}, \mathrm{CRP}+\mathrm{NPK}$ and SCPR increased total $\mathrm{N}$ by 19,47 and $35 \%$, respectively, contrasting decreases of 51 and $67 \%$ for $\mathrm{CPR}+\mathrm{AS}$ and $\mathrm{C}$, respectively. CPR+SSP, CRP+NPK and SCPR increased available $\mathrm{P}$ by 43,33 and 23\%, respectively, contrasting decreases of 44 and $69 \%$ for $\mathrm{CPR}+\mathrm{AS}$ and $\mathrm{C}$, respectively. CPR+SSP, CRP+NPK and SCPR increased exchangeable K by 48, 16 and $32 \%$, respectively, contrasting decreases of 35 and $58 \%$ for $\mathrm{CPR}+\mathrm{AS}$ and $\mathrm{C}$, respectively. $\mathrm{CPR}+\mathrm{SSP}, \mathrm{CRP}+\mathrm{NPK}$ and SCPR increased exchangeable Ca by 41, 27 and 18\%, respectively, contrasting decreases of 50 and $64 \%$ for CPR+AS and C, respectively. CPR+SSP, CRP+NPK and SCPR increased exchangeable $\mathrm{Mg}$ by 38, 32 and 26\%, respectively, contrasting decreases of 32 and $65 \%$ for CPR+AS and C, respectively. CPR+SSP, CRP+NPK and SCPR increased exchangeable Na by 65,58 and $69 \%$, respectively, contrasting decreases of 46 and $65 \%$ for CPR+AS and C, respectively.

Table 4. Chemical properties of the soil as affected by Centrosema pubescens residue and inorganic fertilizers after 2016 cropping season.

\begin{tabular}{|c|c|c|c|c|c|c|c|c|}
\hline \multirow{2}{*}{$\begin{array}{l}\text { Treatments } \\
\text { (CPR+ IF) }\end{array}$} & \multirow[t]{2}{*}{ pH } & \multirow{2}{*}{$\frac{\text { Org. C. }}{\left(\mathrm{g} \mathrm{kg}^{-1}\right)}$} & \multirow{2}{*}{$\frac{\text { Total N }}{\left(\mathrm{g} \mathrm{kg}^{-1}\right)}$} & \multirow{2}{*}{$\frac{\text { Avail. } \mathbf{P}}{\left(\mathrm{mg} \mathrm{kg}^{-1}\right)}$} & \multicolumn{4}{|c|}{ Exchangeable bases $\left(\mathrm{cmol} \mathrm{kg}^{-1}\right)$} \\
\hline & & & & & $\mathrm{K}$ & $\mathrm{Ca}$ & $\mathrm{Mg}$ & $\mathrm{Na}$ \\
\hline Check & $3.5 \mathrm{e}$ & $0.28 \mathrm{c}$ & $0.14 \mathrm{e}$ & $0.19 \mathrm{e}$ & $0.13 \mathrm{e}$ & $0.16 \mathrm{~d}$ & $0.12 \mathrm{c}$ & $0.09 \mathrm{c}$ \\
\hline SCPR & $8.4 \mathrm{c}$ & $0.85 \mathrm{a}$ & $0.58 \mathrm{~b}$ & $0.75 \mathrm{c}$ & $0.41 \mathrm{c}$ & $0.52 \mathrm{~b}$ & $0.43 a$ & $0.44 \mathrm{a}$ \\
\hline $\mathrm{CPR}+\mathrm{AS}$ & $4.5 \mathrm{~d}$ & $0.40 \mathrm{~b}$ & $0.21 \mathrm{~d}$ & $0.34 d$ & $0.20 \mathrm{~d}$ & $0.22 \mathrm{c}$ & $0.23 b$ & $0.14 b$ \\
\hline $\mathrm{CPR}+\mathrm{NPK}$ & $8.9 \mathrm{~b}$ & $0.87 \mathrm{a}$ & $0.63 \mathrm{a}$ & $0.81 b$ & $0.56 \mathrm{a}$ & $0.56 \mathrm{~b}$ & $0.45 \mathrm{a}$ & $0.41 \mathrm{a}$ \\
\hline $\mathrm{CPR}+\mathrm{SSP}$ & $9.5 \mathrm{a}$ & $0.88 \mathrm{a}$ & $0.51 \mathrm{c}$ & $0.87 \mathrm{a}$ & $0.46 \mathrm{~b}$ & $0.62 \mathrm{a}$ & $0.47 \mathrm{a}$ & $0.43 \mathrm{a}$ \\
\hline
\end{tabular}

Mean values in the same column followed by the same letter(s) are not significantly different at $\mathrm{P}=$ 0.05 (DMRT). CPR+IF, Centrosema pubescens residue+inorganic fertilizer; SCPR, sole Centrosema pubescens residue; CPR+AS, Centrosema pubescens residue+ammonium sulphate, CPR+SSP, Centrosema pubescens residue+single superphosphate. Maize grain yield and yield components as affected by Centrosema pubescens residue and
inorganic fertilizers at harvest

Table 5 shows maize grain yield and yield components as affected by Centrosema pubescens residue and inorganic fertilizers at harvest. Mean values of maize yield data over the two years of experimentation indicated that integrated application of Cenrosema pubescens residue and inorganic fertilizers significantly increased maize grain yield from $0.81 \mathrm{t} \mathrm{ha}^{-1}$ for $\mathrm{C}$ to $1.70,1.91,2.33$ and $2.10 \mathrm{t}$ $\mathrm{ha}^{-1}$ for the respective SCPR, CPR+AS, CPR+NPK and CPR+SSP. Mean values of maize cob length data over the two years of experimentation indicated that integrated application of Cenrosema pubescens residue and inorganic fertilizers significantly increased maize cob length from $8.11 \mathrm{~cm}$ for $\mathrm{C}$ to $9.36,13.92,17.27$ and $15.78 \mathrm{~cm}$ for the respective SCPR, CPR+AS, CPR+NPK and CPR+SSP. Similarly, mean values of maize cob diameter data over the two years of experimentation indicated that integrated application of Cenrosema pubescens residue and inorganic fertilizers significantly increased maize cob diameter from $6.13 \mathrm{~cm}$ for $\mathrm{C}$ to $8.06,11.09,14.77$ and $14.27 \mathrm{~cm}$ for the respective SCPR, CPR+AS, CPR+NPK and CPR+SSP. 
Evaluating Potentials of Integrated Application of Plant Residues and Inorganic Fertilizers in Enhancing Soil Fertility Status and Maize (Zea mays L.) yield

Table 5. Maize grain yield and yield components as affected by Centrosema pubescens residue and inorganic fertilizers at harvest.

\begin{tabular}{|c|c|c|c|c|c|c|c|c|c|}
\hline \multirow{2}{*}{$\begin{array}{l}\text { Treatments } \\
(\text { CPR+ IF })\end{array}$} & \multicolumn{3}{|c|}{ Maize grain yield $\left(\mathrm{t} \mathrm{ha}^{-1}\right)$} & \multicolumn{3}{|c|}{ Maize cob length $(\mathrm{cm})$} & \multicolumn{3}{|c|}{ Maize cob diameter $(\mathrm{cm})$} \\
\hline & 2015 & 2016 & Mean & 2015 & 2016 & Mean & 2015 & 2016 & Mean \\
\hline Check & $0.88 \mathrm{e}$ & $0.73 \mathrm{e}$ & 0.81 & $8.21 \mathrm{e}$ & $8.00 \mathrm{e}$ & 8.11 & $6.23 \mathrm{e}$ & $6.03 \mathrm{e}$ & 6.13 \\
\hline SCPR & $1.61 \mathrm{~d}$ & $1.78 \mathrm{~d}$ & 1.70 & $9.30 \mathrm{~d}$ & $9.42 \mathrm{~d}$ & 9.36 & $8.00 \mathrm{~d}$ & $8.12 \mathrm{~d}$ & 8.06 \\
\hline $\mathrm{CPR}+\mathrm{AS}$ & $1.89 \mathrm{c}$ & $1.93 \mathrm{c}$ & 1.91 & $13.86 \mathrm{c}$ & $13.98 \mathrm{c}$ & 13.92 & $11.01 \mathrm{c}$ & $11.16 \mathrm{c}$ & 11.09 \\
\hline $\mathrm{CPR}+\mathrm{NPK}$ & $2.29 \mathrm{a}$ & $2.37 \mathrm{a}$ & 2.33 & $17.21 \mathrm{a}$ & $17.33 \mathrm{a}$ & 17.27 & $14.71 \mathrm{a}$ & $14.83 \mathrm{a}$ & 14.77 \\
\hline $\mathrm{CPR}+\mathrm{SSP}$ & $2.05 \mathrm{~b}$ & $2.14 b$ & 2.10 & $15.71 \mathrm{~b}$ & $15.84 b$ & 15.78 & $14.21 \mathrm{~b}$ & $14.33 b$ & 14.27 \\
\hline
\end{tabular}

Mean values in the same column followed by the same letter(s) are not significantly different at $\mathrm{P}=$ 0.05 (DMRT). CPR+IF, Centrosema pubescens residue+inorganic fertilizer; SCPR, sole Centrosema pubescens residue; CPR+AS, Centrosema pubescens residue+ammonium sulphate, CPR+SSP, Centrosema pubescens residue+single superphosphate

\section{DISCUSSION}

The chemical properties of soil in the study site, prior to cropping indicated that the soil was slightly acidic, with a $\mathrm{pH}$ of 5.7. The soil organic carbon (SOC) value of $0.71 \mathrm{k} \mathrm{kg}^{-1}$ was below the critical level of $5.8 \mathrm{~g} \mathrm{~kg}^{-1}$ for soils in southwestern Nigeria (Geis, 2012; Awani, 2012). The total nitrogen of $0.43 \mathrm{~g} \mathrm{~kg}^{-1}$ was below the $1.5 \mathrm{~g} \mathrm{~kg}^{-1}$ critical level reported by Atete (2012). The $\mathrm{K}$ value of $0.31 \mathrm{cmol}$ $\mathrm{kg}$ was below the $0.86 \mathrm{cmol} \mathrm{kg}$ critical level reported by Atete (2012). The $\mathrm{Ca}, \mathrm{Mg}$ and $\mathrm{Na}$ values were all below the established critical levels for soils in southwestern Nigeria (Lege, 2012).

Relative to the initial nutrient status of the soil, prior to 2015 cropping season, the decreases in the soil $\mathrm{pH}$ (i.e. increased acidity), observed in the plots of control and CPR+AS treatments, after cropping, agree with the findings of Marsus (2011) and Abbet (2012), who reported increased soil acidity (i.e. decreased $\mathrm{pH}$ ) of soil in the control and CPR+AS plots, after cropping. The decreases in the $\mathrm{pH}$ values of soil in the control and CPR+AS plots can be ascribed to decreases in exchangeable bases, after cropping. The decreases in the exchangeable bases, associated with the control and CPR+AS treatments can be attributed to uptake of the exchangeable bases by maize during the growing period. Much as the decreases in the soil $\mathrm{pH}$, after cropping, observed in the plots of CPR+AS and the control can be adduced to uptake of the exchangeable bases by maize, however, another factor that can be implicated for the increased soil acidity, associated with CPR+AS and the control treatments, is the acidifying effects of ammonium sulphate fertilizer on soil, through release of hydrogen ions $\left(\mathrm{H}^{+}\right)$, following oxidation of ammonium ion $\left(\mathrm{NH}_{4}{ }^{+}\right)$component of ammonium sulphate fertilizer [( $\left.\left(\mathrm{NH}_{4}\right)_{2} \mathrm{SO}_{4}\right]$ (Marsus, 2011; Abbet, 2012).

Conversely, after cropping, soil $\mathrm{pH}$ values increased in the plots of SCPR, CPR+NPK and CPR+SSP. These increases in soil $\mathrm{pH}$ can be adduced to the release of the exchangeable bases by Centrosema pubescens residues on decomposition. Similar findings had earlier been reported by Nottidge et al; (2010); Balogun (2012) and Abbet (2012), who reported significant increases in soil pH and base saturation due to increases in exchangeable bases, following addition of residues of certain tropical legumes. These observations suggest that, residues of Centrosema pubescens have liming effects on soil, in addition to enhancing soil fertility or increasing nutrient availability in the soil.

The increases in the soil organic carbon (SOC), observed in the plots of SCPR, CPR+NPK and $\mathrm{CPR}+\mathrm{SSP}$ can be attributed to increases in soil organic matter (SOM), following decomposition of Centrosema pubescens residues. These observation corroborated the findings of Nottidge et al; (2010); Balogun (2012). On the contrary, SOC decreased in the plots of CPR+AS and control. The decreases in SOC, adduced to CPR+AS and control treatments can be explained in the light of increased soil acidification (decreased $\mathrm{pH}$ ), associated with $\mathrm{CPR}+\mathrm{AS}$ and control treatments. This is because, previous studies (Nana, 2011; Awani, 2012) had established that, the rate of organic matter decomposition, and hence, SOC value, depends on $\mathrm{pH}$ of the soil medium, with the rate of organic matter decomposition by soil microbes decreasing with increasing soil acidity (i. e. decreasing $\mathrm{pH}$ ). These authors also opined that the rate of organic matter decomposition becomes almost negligible at soil $\mathrm{pH}$ value below 5.1. So, the lower $\mathrm{pH}$ values (higher acidity) of soil in the plots of CPR+AS and control treatments can be implicated for the observed lower SOC values for CPR+AS and control treatments, since this condition of higher acidity in the plots of CPR+AS and control treatments may 
Evaluating Potentials of Integrated Application of Plant Residues and Inorganic Fertilizers in Enhancing Soil Fertility Status and Maize (Zea mays L.) yield

have impaired microbial decomposition of the native organic matter of soil in the plots of CPR+AS and control treatments, with resultant lower SOC values.

The increases in total $\mathrm{N}$, available $\mathrm{P}$ and exchangeable bases for SCPR, CPR+NPK and CPR+SSS, after cropping, are in conformity with the reports of Nottidge et al; (2010); Pestov (2012), who reported increases in these plant nutrients for SCPR, CPR+NPK and CPR+SSS after cropping. The increases in these nutrients after cropping, adduced to SCPR, CPR+NPK and CPR+SSS treatments can be explained in the light of the increases in SOC/SOM, recorded in the plots of SCPR, CPR+NPK and CPR+SSS treatments. This is because previous studies (Dada, 2011, Phi, 2012) had reported SOM as a reservoir or natural source of other nutrients; that is, other nutrients are integrally tied to it. Thus, the maintenance of SOM is paramount in sustaining other soil quality factors (Dada, 2011).

The decreases in virtually all the plant nutrients after cropping, adduced to CPR+AS treatment can be attributed to poor nutrient release of Centrosema pubescens residues, due perhaps, to the acidifying effects of ammonium sulphate fertilizer, which in turn, may have inhibited microbial decomposition of Centrosema pubescens residues, with resultant low nutrient release.

The higher percentage increases in SOC, total N, available $\mathrm{P}$ and exchangeable bases for SCPR, CPR+NPK and CPR+SSP at the end of the second year (2016) cropping season, compared to what obtained in the first year (2015) cropping season, for SCPR, CPR+NPK and CPR+SSP, can be explained in the light of the residual effects of the first year (2015) Centrosema pubescens residues application, coupled with the additional Centrosema pubescens residues application in the second year.

The significantly higher maize grain yield and yield components for CPR+NPK, CPR+AS and CPR+SSP than that for SCPR, are in conformity with the findings of Marsus (2011) and Abbet (2012). These observations can be explained in the light of complementary roles of integrated application of organic fertilizer (Centrosema pubescens residues) and inorganic fertilizers (NPK, ammonium sulphate and single superphophate) in maintaining soil fertility, and hence, enhancing crop productivity. This is because, the complementary use of organic and inorganic fertilizers increases water and nutrient use efficiency, with the organic fertilizer component increasing the organic matter content of the soil, as well as providing certain essential micronutrients which are not present in inorganic fertilizers (Geis, 2012; Abbet, 2012). Futhermore, the complementarity of organic and inorganic fertilizers satisfies immediate nutrient requirements of crops, as the inorganic fertilizer component releases its nutrients faster than the organic fertilizer component, thus, making nutrients more readily available to plants (Geis, 2012; Abbet, 2012). The higher maize grain yield and yield components for SCPR, CPR+NPK, CPR+AS and CPR+SSP, recorded in the second year (2016), can be ascribed to higher soil fertility level in the second year (2016), due to the residual effects of the previous year (2015 application of Centrosema pubescens residues, coupled with the additional application of Centrosema pubescens residues in the second year. On the contrary, maize grain yield in the first year (2015) cropping season under the control treatment was higher than what obtained in the second year (2016) under the control. This can be explained in the light of declined soil fertility in the second year as a result of nutrient removal by maize in the preceding year (2015).

\section{REFERENCES}

Abbet, N. (2012): Evaluation of fertility status of an Alfisol and maize performance under different plant residue management techniques. Journal of Agriculture and Forestry. 11(2):6 - 11.

Adenle, A.A. (2010): Influence of integrated application of Gliricidia sepium residues and poultry manure on nutrient status of an Alfisol and maize yield. Soil Fertility Research. 12: $80-86$.

Aina, P.A. (2008): Tree legume residues effects on soil physical and chemical properties and yield of maize in an Alfisol. Journal of Applied Science. 15:33 -40.

Ame, A.D. (2012): Soil physical and chemical properties as affected by legume residues. Soil and Environmental Research. 6:22 - 28.

Aribe, M.N. (2003): Soil fertility and maize performance under tillage practices and plant residues management techniques. Soil Fertility. 27:200 - 206.

Atete, B.O. (2005): Enhancing fertility of an acid Alfisol and maize performance through integrated application of cattle manure and urea. Soil Science. 21(1): 251 -259. 
Evaluating Potentials of Integrated Application of Plant Residues and Inorganic Fertilizers in Enhancing Soil Fertility Status and Maize (Zea mays L.) yield

Awani, U.S. (2012): Organic matter dynamics and maize yield under plant residue management techniques and NPK fertilization. Soil Resources. 14:30- 37.

Balogun, J.R. (2012): Assessment of fertility status of an Alfisol under plant residues and NPK Fertilization. Soil Science. 13: 6 - 12.

Dada, EO. (2011): Soil organic matter dynamics and cassava performance under plant residue management techniques. Soil Organic Matter Dynamics. 23: 100 - 106.

Geis, F.O. (2012): Responses of fertility status of an Alfisol and maize performance to plant residue management techniques. Soil and Land Development. 22(2):1 -7.

Guman, H.O. (2011): Comparative effects of plant residues on soil and leaf nutrient content and maize yield. Fertilizer and Environmental Research. 23:44 - 52.

International Institute of Tropical Agriculture (IITA) (1989). Automated and semi - automated methods soil and plant analysis. Manual Series. No 7, IITA, Ibadan, Nigeria.

Kader, B.R. (2012): Phosphorus requirements of groundnut and soybean as affected by $\mathrm{N}$ nutrition. Plant Nutrition. 23: $44-49$.

Keary, M.R. (2014): An investigation into the use of plant residue and wood ash for improving soil conditions and productivity of maize in Nigeria. Soil Fertility Management. 24: 333 -339.

Lege, B.N. (2012): N, P, and K mineralization and maize grain yield following application of Gliricidia sepium residues to an acid Alfisol in southwestern Nigeria. Soil Fertility and Plant Nutrition. 21:6 -14

Marsus, M.S. (2011): Effects of incorporating legume hedgerows prunings on chemical properties of an Alfisol in Nigeria. Food and Agricultural Research. 11(1):1 - 7.

Nana, G.O. (2011): Assessment of the potential of tree prunings in ameliorating degreded Alfisol. International Journal of Agriculture and Food Technology. 15(1): $34-41$

Nottidge, D.O., Ojeniyi, S.O. and Asawalam, D.O. (2010): Effects of different woodash levels on Nutrient content of maize and geain yield in an acid Alfisol. Nigerian Journal of Soil Science.17: 98 - 103

Pestov, J.C. (2012): Responses of fertility status of an Alfisol and maize performance to plant residue management techniques. Soil and Land Development. 22(2):1 -7.

Phi, S.U. (2012): Effects of incorporating legume hedgerows prunings on chemical properties of an Alfisol in Nigeria. Food and Agricultural Research. 11(1):1 - 7.

Singh, P. (2005): Improving soil fertility and maize yield performance through Chromolaena odorata residues. International Journal of Food and Agricultural Research. 10(2): 60- 70.

Soil Survey Staff (SSS): Keys to soil taxonomy, $9^{\text {th }}$ edition. USDA Natural Resources Conservation Services, US Department of Agriculture, Washington D.C.306 pp.

Udeata, F. (2008): N mineralization and maize yield, following application of tree prunings to a sandy Loam soil in Nigeria. Agroforestry Systems. 21(2): 212 - 219.

Citation: B. Osundare, F.O. Fawole, "Evaluating Potentials of Integrated Application of Plant Residues and Inorganic Fertilizers in Enhancing Soil Fertility Status and Maize (Zea mays L.) yield ", International Journal of Research Studies in Agricultural Sciences, vol. 4, no. 2, p. 27-33, 2018. http://dx.doi.org/10.20431/24546224.0402004

Copyright: () 2018 B. Osundare, F.O. Fawole. This is an open-access article distributed under the terms of the Creative Commons Attribution License, which permits unrestricted use, distribution, and reproduction in any medium, provided the original author and source are credited. 